EVS26

Los Angeles, California, May 6-9, 2012

\title{
Assessing range and performance of electric vehicles in Nordic driving conditions - Project "RekkEVidde"
}

\author{
Juhani Laurikko ${ }^{1}$, Robert Granström ${ }^{2}$, Arto Haakana ${ }^{3}$ \\ I'corresponding author)VTT, FI-02044VTT, Espoo, Finland, juhani.laurikko@vtt.fi \\ ${ }^{2}$ TSS North, SE-930 90 Arjeplog, Sweden, robert.granstrom@testsitesweden.com \\ ${ }^{3}$ GreenNet Finland, FI-01510 Vantaa, Finland, arto.haakana@greennetfinland.fi
}

\begin{abstract}
Until battery technology makes a leap, shortage of range is by far the greatest flaw in electric vehicle technology that is otherwise very effective and promising. However, energy use is also highly dependent on duty cycles, driving conditions and traffic situation. Furthermore, cabin heating in an EV will not be supported by energy losses as in an ICE-car. Therefore, actual range can differ substantially in real-life situations, and can be much shorter than the official figures given by the manufacturers. Project RekkEVidde is aiming at drafting a testing scheme to address EV driving in Nordic conditions, and produce realistic range estimates for the consumers to help them understand and make better use of this raising technology.

Initial laboratory testing was imposed on a Citroën C-Zero EV using multiple different driving cycles and testing also at $-20{ }^{\circ} \mathrm{C}$, not just the normal ambient. First review of the results in this paper shows that the energy consumption was raised on average some $30 \%$ at low ambient, resulting to a 15 to $30 \%$ shorter range. This was due to only increasing the air drag component according to increase in air density, but further on-road testing will also give us more information on increase of rolling resistance because of snow and ice packed on road surface. Furthermore, use of cabin heating was not included in these numbers. Should it be turned on, the range will be further shortened as much as $50 \%$ in slow-speed urban driving.
\end{abstract}

$E V$, range, cold driving conditions, laboratory testing, field testing

\section{Introduction}

Electric vehicles are still immature compared to IC-driven cars regarding range. State of the art products as the Tesla Roadster offers close to 400 $\mathrm{km}$ on one charge [1], and their upcoming "Model X" is touted to go up to $500 \mathrm{~km} \mathrm{[2].} \mathrm{But} \mathrm{focus-}$ ing on a decent total cost of ownership, rangefigures between 100 and $160 \mathrm{~km}$ is what you can expect today, and probably for the foreseeable future.

Energy use is also highly dependent on duty cycles, driving conditions and traffic situation.
Furthermore, cabin heating in an EV will not be supported by energy losses as in an ICE-car. Therefore, actual range can differ substantially in real-life situations, and can be much shorter than the official figures given by the manufacturers. Besides, there is no reserve or possibility to lend "fuel" for a stranded EV from a by-passer. Thus an EV-user needs to know for sure how far the vehicle will go, also in the worst possible conditions. Thus, "range anxiety" is common among those who already use EVs or consider one.

We believe that a realistic estimate of the range is the most critical factor for EV's success, but because of this disparity in range, the industry is 
tempted to quote (over)optimistic figures. However, if the numbers do not reflect the true performance and the customers are in practice seeing drastically lower driving ranges than those advertised, there is a danger that the marketacceptance of EVs suffers strongly.

Therefore, assessing vehicle performance using most realistic driving patterns and weather conditions, including especially low ambient temperatures, is essential. Otherwise, this may even cause a backfire effect to the deployment of EVs. Accurate and realistic information of range is also needed for the process of planning and calculating the capacity of the charging infrastructure, as well as spatial allocation of the charging points. Station-to-station distances need to be in relation to the actual ranges of the vehicles in all conditions. In extreme situations local conditions may lower the range of EVs, and the density of the charging network needs to be increased to guarantee all-year trouble-free operations.

\section{Present-day status}

\subsection{Official testing of $\mathrm{EV}$ range}

Currently there are no common global test protocols for fuel or energy consumption measurements of passenger cars, although the World Forum for Harmonization of Vehicle Regulations of the United Nation Economic Commission for Europe (UN/ECE/WP29) has brought governments and vehicle manufacturers together to work on a new global test procedure. However, it may still take several years before agreement on a global testing method can be reached. In the meantime there will still be several testing methods in use according to the market area.

Today in the European Union, the energy use of cars, both ICE-driven and electrically-powered, is measured according to UN-ECE Reg. 101. It prescribes a laboratory test, performed in normal ambient conditions (temperature between +20 and $+30^{\circ} \mathrm{C}$ ), and using a duty-cycle composed of an urban and extra-urban sub-cycle originating from a pan-European exhaust emissions regulation (UNECE Reg. 83 and 98/69/EC).

Although primarily set to measure energy consumption, the protocol today includes also determination of range for electric-powered vehicles. As for normal ICE-driven cars, range is not an issue. Most of the cars will go more than 500 $\mathrm{km}$ on a tankful of fuel, and the extremely frugal diesels can today raise their range up to four digit figures.

\subsection{OEM's figures for $\mathrm{EV}$ range}

In addition to the official figures, EV manufacturers have today started to quote also figures for range resulting from their own testing. However, those are not comparable to each other. For example for the "twinning" of Peugeot Ion/Citroën CZERO, the current range given by the manufacturer is $150 \mathrm{~km} \mathrm{[3].} \mathrm{However,} \mathrm{it's} \mathrm{worth} \mathrm{noting} \mathrm{the}$ disclaimer which states, "Range varies according to climatic conditions, driving style, the use of electrical equipment, the frequency of normal or fast charges and ageing of the main battery".

On the other hand for the original "master-car" itself, Mitsubishi iMiEV, the range quoted for the Japanese market is $160 \mathrm{~km}$ (100 miles) [4], even if they are all technically similar vehicles with equal battery capacity. The reference is then the Japanese 10.15 cycle having lower speeds than its European counterpart. For the recent entry to the U.S. market, the official EPA sanctioned range is only 100 $\mathrm{km}$ (60 miles) [4].

Energy need also differs between vehicles. Think City weights as much as the iMiEV, but has $40 \%$ more battery capacity $(23 \mathrm{kWh}$ vs. $16 \mathrm{kWh}$ in $\mathrm{iMiEV})$. Yet the promised range is about the same, $160 \mathrm{~km}$ for both cars.

Furthermore, Nissan has recently released in U.S. new range figures for their EV Leaf, referring to 6 different types of driving vs. weather conditions, ending up to 6 different ranges between 47 miles and 138 miles depending on the particular case [5]. Having a common Nordic protocol could help the industry to test their products in a harmonised way, instead of each having their own tests.

\section{Project "RekkEVidde"}

\subsection{The Nordic Countries}

The five Northern European countries Sweden, Norway, Denmark, Finland and Iceland are known as The Nordic Countries, and sometimes also referred as "Norden". Their climatic conditions are highly variable, and contain also lots of snow and low temperatures that have definitely an adverse impact on motoring. Yet those countries are highly developed market economies, where daily routines like transport and traffic are expected to go on as usual, irrespectively of the prevailing weather.

Because of the similarities in climate and in many social and economic structures these countries have lots of co-operation e.g. in R\&D. As part of this kind of Nordic co-operation a project addressing the subject of the disparity found in the range of EV's and need to give solid consumer infor- 
mation was initiated in 2011. It is funded by the Nordic Energy Research (NER) council by its Energy\&Transport Programme, and participants come from all other Nordic countries but Denmark. The project was named "RekkEVidde"; i.e. "range" in Norwegian language.

\subsection{Objectives of the work}

The main objective of the project work is to address key parameters affecting to the energy use in an EV, and in parallel collect data from the real-world driving conditions around the Norden. The goal is combine these datasets and to build a system that will produce realistic performance figures for EVs attributed to Nordic driving and weather conditions. The work within the project is actually targeting to a reduction of necessary test to be performed for comparison by defining common testing protocol. This is intended to help the industry to reduce their individual testing activities, and at the end design and build EV's suitable for the Nordic region.

Battery degradation and decay in range shall also be assessed because if performance fails considerable during use, the rest value of a used vehicle shall drastically devaluate, resulting among other things higher leasing payments. We envisage that the project will also help the industry to verify their SOC-meter (State of Charge), which is calculated and related to a supposed energy capacity. This is probably as important for the range anxiety as the range itself.

\subsection{Main contents of the work}

The work itself can be divided into four different main tasks.

\subsubsection{Task 1 - Data collection}

Task 1 is collecting data from the environmental condition across the Nordic countries as well as from typical use of both EVs and regular cars, as well. The climate data will be based on weather bureau statistics, but most of the data on the use of cars will be based on parallel projects now underway that address this theme. Most prominent of these is the "Bilrörelsedata" (Car Movement Pattern Data) in Sweden.

\subsubsection{Task 2 - Nordic Test Protocol}

Task 2 deals with the development of the actual test protocol and other evaluation tools. Test cycles and set of test conditions reflecting real world use are developed using data from Task 1. These will be fused to a test protocol addressing
EV performance in typical Nordic conditions. It shall produce realistic estimates of energy use and enable calculations of range in different conditions. Parallel to this, in-vehicle data collection methodology and devices will be formulated following the experience from "Bilrörelsedata", and data transfer \& handling practices will be developed. The aim is to verify that the figures from the in-laboratory tests match with true in-use values.

\subsubsection{Task 3 - Testing of Candidate EVs}

Task 3 entails application of the developed test protocol on some candidate vehicles. EV types that represent expected market offerings in Nordic countries will be chosen. One of each type is subjected to the detailed in-laboratory testing using the newly developed protocol.

\subsubsection{Task 4 - Field Test of EVs}

Task 4 is a field test of EV's in Nordic conditions. A suitable sized control group of EVs is equipped for the parallel in-field testing. This should involve all participating countries. An invitation will also be sent to selected group of EV users to broaden the in-use data retrieval outside main control fleet. Electronic driver feedback system will be used to collect information from this pool, and an internet server for data input will be set up.

\section{Testing Activities}

\subsection{Laboratory test set-up}

Technical Research Centre of Finland (VTT) has a climatic test cell for passenger car energy and exhaust emission measurements. It is equipped with a single-roller dynamometer with $1.0 \mathrm{~m}$ diameter rollers. Ambient temperature in the cell can be controlled between +25 and $-30{ }^{\circ} \mathrm{C}$, and cooling air circulation is available at speeds up to 100 $\mathrm{km} / \mathrm{h}$, constant or relative to the roller speed equalling driving speed. The range for inertia simulation is from $450 \mathrm{~kg}$ to $2500 \mathrm{~kg}$, which makes it suitable for testing of all kinds of EVs, also the lightweight concepts.

Initial laboratory testing for this project was imposed on a Citroën C-Zero. The car was factory standard with all optional heating and ventilation accessories. Before testing the car was run-in for some $1200 \mathrm{~km}$ on normal roads in Helsinki Metropolitan area in November-December 2011.

Figures 1 and 2 show the car in the test cell with probes and other instrumentation for energy measurements also within the propulsion system itself. 


\subsection{Driving cycles}

To assess the effect of driving cycle a set of existing duty-cycles were exploited. The base cycle was the official test cycle, i.e. European driving cycle consisting of urban part (ECE15) and an extra-urban part (EUDC). In addition, two local Finnish cycles were used, one for urban (HelsinkiCity) and on for road and highway-type of driving (Highway.FIN). Further two three cycles were sourced from the European ARTEMISproject that developed a set of "representative" cycles in early 2000 for measuring exhaust emissions from cars. They were supposed to portray urban, road and motorway driving. Figs 3 to 6 illustrate all cycles imposed.

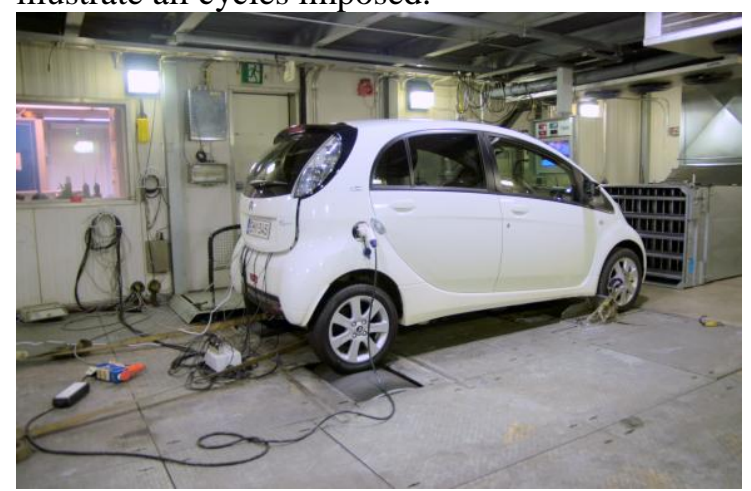

Figure 1. Citroën C-Zero on in test cell at VTT.

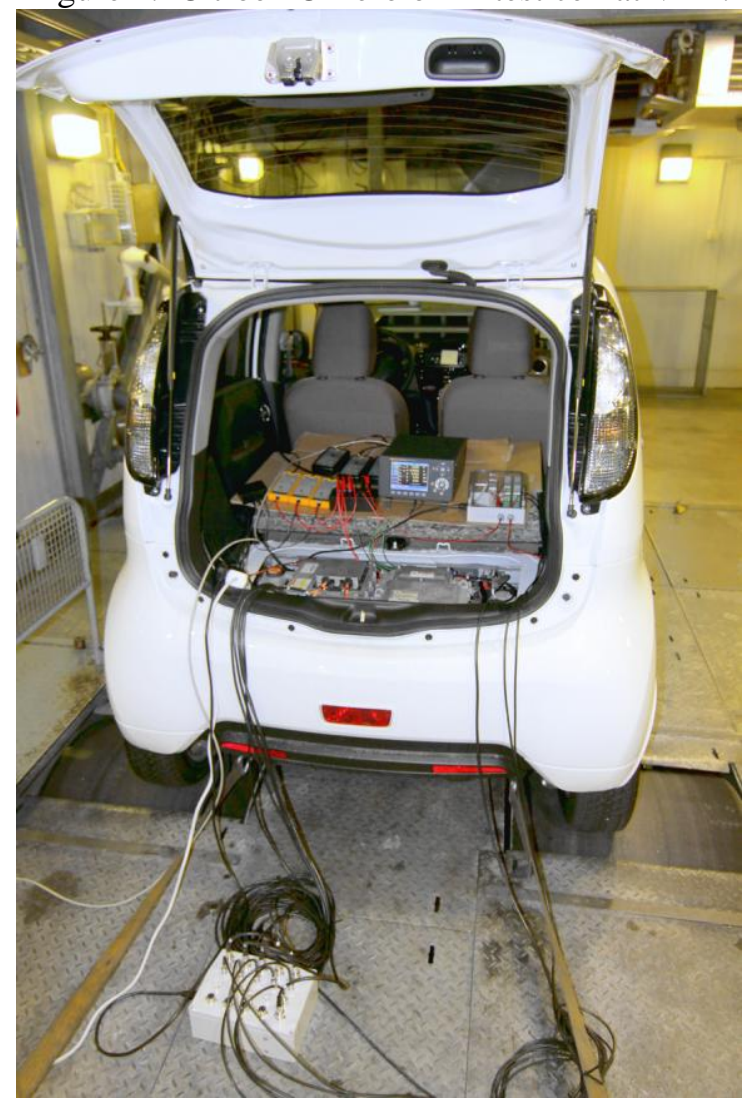

Figure 2. Some of the measurements apparatus.

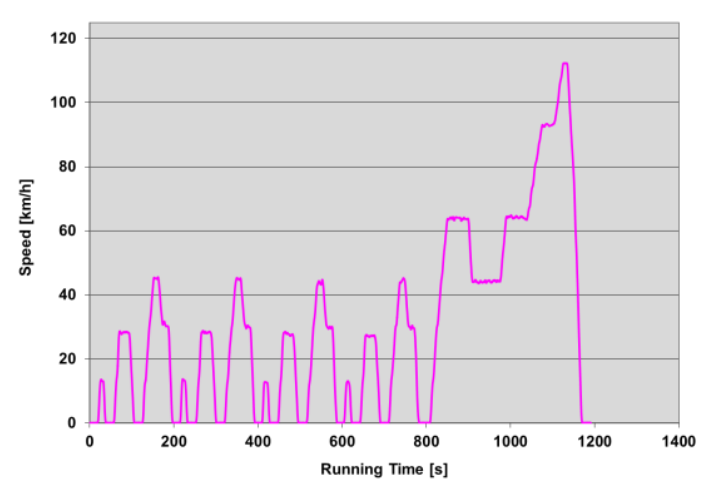

Figure 3. European driving cycle

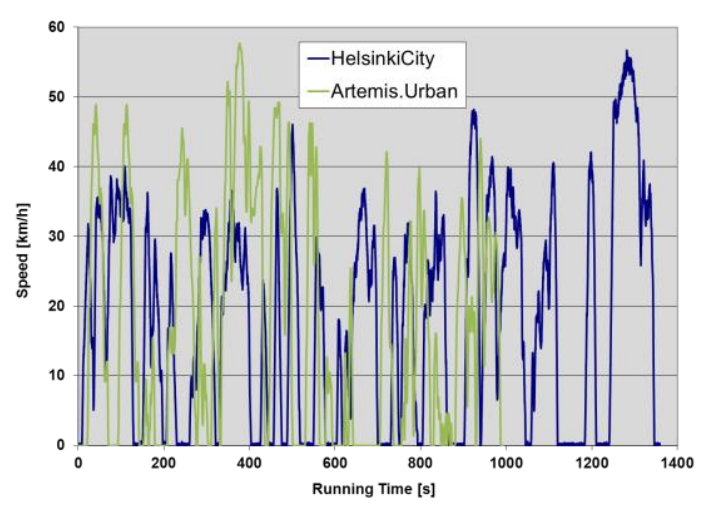

Figure 4. Urban cycles

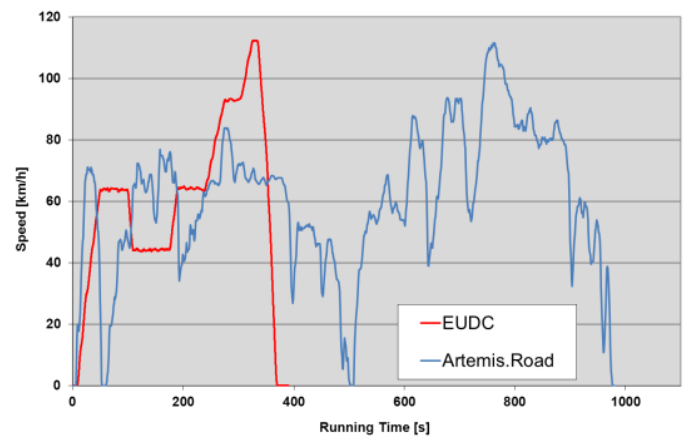

Figure 5. Road cycles

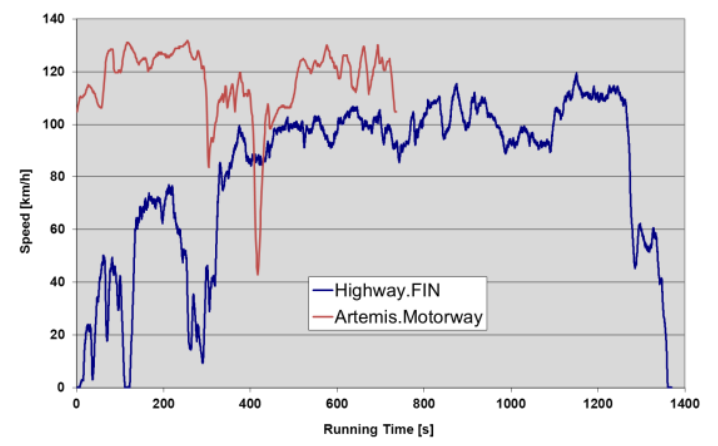

Figure 6. Highway cycles. 
Table 1 lists main characteristics of the cycles used in preliminary testing.

Table 1. Characteristics of the driving cycles.

\begin{tabular}{|l|r|r|r|r|r|}
\hline & Distance & $\begin{array}{r}\text { Average } \\
\text { Speed } \\
\mathrm{km} / \mathrm{h}\end{array}$ & $\begin{array}{r}\text { Maximum } \\
\text { Speed } \\
\mathrm{km} / \mathrm{h}\end{array}$ & $\begin{array}{r}\text { Stops } \\
\text { during } \\
\text { cycle }\end{array}$ & $\begin{array}{r}\text { Run } \\
\text { Time }\end{array}$ \\
\hline EUcle & 11.007 & 33.6 & 120 & 12 & 1180 \\
\hline ECE15 & 4.052 & 18.7 & 50 & 4 & 780 \\
\hline EUDC & 6.955 & 62.6 & 120 & 0 & 400 \\
\hline Helsinki City & 6.600 & 19.1 & 55 & 17 & 1360 \\
\hline Artemis Urban & 4.488 & 17.6 & 58 & 19 & 993 \\
\hline Road, FIN & 24.800 & 81.3 & 120 & 1 & 1370 \\
\hline Artemis Road, EV & 16.641 & 60.3 & 111 & 1 & 981 \\
\hline Artemis Motorway, $\mathrm{EV}^{*}$ & 23.793 & 105.6 & 130 & 0 & 736 \\
\hline
\end{tabular}

\subsection{Test conditions}

The initial phase of the in-lab testing was conducted at two ambient temperatures: +23 and -20 ${ }^{\circ} \mathrm{C}$. Relative humidity in the test cell was controlled to agree with the requirements of ECE R101.

Setting of the dynamometer road load was made against coast-down data obtained from a similar car on flat road conditions, and the final setting of the bench agreed with those coast-down times observed. Also the 0 to $100 \mathrm{~km} / \mathrm{h}$ acceleration times equalled results from on-road measurements.

For the tests at $-20{ }^{\circ} \mathrm{C}$ the air drag factor was increased by about $10 \%$ to match with the increased density of the air at that given temperature compared to normal temperature. No other adjustments were made. However, in real conditions also rolling resistance would be higher, because road surface friction would probably increase due to the packing of the ice and snow. This effect will be investigated during the project later on with on-road measurements, and the effect shall be taken in also in the future lab measurements.

Furthermore, in this test series the on-board cabin heater was not used, even if the driving at low temperatures more than a few minutes surely requires it. This choice was made to more clearly differentiate the various contributions to the increase of total energy consumption, and its eventual effect on shortening of the range. Moreover, to make the driving conditions acceptable and to match the minimum ambient temperature limits of the instruments used in the exercise, a separate heater/blower using $230 \mathrm{~V}$ grid electricity was used. Energy use of the on-board cabin heater was measured separately, and its effect is superimposed on the results.

\section{Summary of Results}

The analysis of the measurement results so far entail only comparison of gross energy use of the various driving cycles at both ambient temperatures, as well as calculation of range based on the amount of energy that the traction battery was able to deliver until fully drained.

Table 2 encompasses results for specific energy use over each cycle at both test temperatures. The energy use has been calculated from the uptake of grid electricity after driving of each cycle three times in series with a 2 minute pause in between. However, the Artemis.Motorway cycle was so demanding that traction battery was depleted before reaching the end of the third run. At normal temperature the car could reach $3 / 4$ of the cycle, but at sub-zero temperature, the third run was limited to a mere $1.4 \mathrm{~km}$.

Table 2 Specific energy use (uptake from grid) for each cycle at +23 and $-20{ }^{\circ} \mathrm{C}$.

\begin{tabular}{|l|cc|c|}
\hline \multicolumn{4}{|c|}{ each cycle at +23 and -20} \\
\hline
\end{tabular}

${ }^{*} \mathrm{EV}$ denotes that warm-up part of the cycle is omitted

When we look at the figures in table 2, and especially compare results measured at -20 we can see that need for energy uptake from the grid to cover energy need to run the given cycle increased on average by some $30 \%$, when ambient temperature was lowered from +23 to $-20{ }^{\circ} \mathrm{C}$. Most notable increase was seen in European test cycle $(+41 \%)$, while in case of the HelsinkiCity "urban crawl" cycle we saw less than $20 \%$ raise.

We have also calculated nominal ranges for each case dividing the capacity of the traction battery measured at both conditions with the cycle-specific energy uptake. Even if the use of energy seemed to increase while the ambient temperature was lowered, traction battery capacity seemed to sustain at the same level. After fully depleting the battery for a few times at both temperatures, the amount of grid energy uptake was on average $17.6 \mathrm{kWh}$ in both cases. However, somewhat longer time was needed at low temperature to reach $100 \%$ SOC compared to normal ambient. The reason is the limiting of the charging current that the car manu- 
facturer has built in the system. It shuts down the charging completely at $-25{ }^{\circ} \mathrm{C}$. The calculated estimates for range in each case are shown in Table 3.

Table 3 Estimated range for each cycle at +23 and $-20{ }^{\circ} \mathrm{C}$.

\begin{tabular}{|l|c|c|c|}
\hline & \multicolumn{2}{|c|}{ estimated range } & difference \\
& $+23 \mathrm{C}$ & $-20 \mathrm{C}$ & -20 vs. +23 \\
& $\mathrm{~km}$ & $\mathrm{~km}$ & $\%$ \\
\hline EUcle & 124 & 88 & $-29 \%$ \\
\hline Helsinki City & 125 & 106 & $-15 \%$ \\
\hline Artemis Urban & 99 & 74 & $-26 \%$ \\
\hline Road, FIN & 91 & 70 & $-23 \%$ \\
\hline Artemis Road, EV* & 113 & 90 & $-20 \%$ \\
\hline Artemis Motorway, EV* & 72 & 53 & $-26 \%$ \\
\hline average, all cycles & 100 & 79 & $-21 \%$ \\
\hline
\end{tabular}

*EV denotes that warm-up part of the cycle is omitted

When looking at the results in Table 3, we see that the estimated range can differ from a high of $125 \mathrm{~km}$ for Helsinki.City cycle at normal temperature to a low of $53 \mathrm{~km}$ in Artemis.Motorway at $-20{ }^{\circ} \mathrm{C}$. Also if we compare the relative shortening of the range in each cycle case, we see that the range will fall short by some $20 \%$ on average, while at worst it can be as much as nearly 30 $\%$ shorter, when the weather is cold.

As said before, all these measurements were done without the heater on. If we would employ also the heater at low ambient conditions, a further reduction in range would be seen. The nominal power of the PTC-heater is some $4.5 \mathrm{~kW}$, and taking into account the average speed in each cycle, we can estimate the heater will draw additionally some $0.25 \mathrm{kWh} / \mathrm{km}$ in slow urban cycles and around $0.06 \mathrm{kWh} / \mathrm{km}$ in road/motorway cycles with higher speed. This will raise the total energy use quite substantially, especially in urban crawl, where the total is more than doubled because of the heater. Table 4 summarises the results of this exercise.

Table 4 Energy use of heater and its impact on range at $-20^{\circ} \mathrm{C}$.

\begin{tabular}{|l|c|c|c|c|}
\hline at $-20^{\circ} \mathrm{C}, 4.5 \mathrm{~kW}$ heater & $\begin{array}{c}\text { heater } \\
\text { energy } \\
\mathrm{kWh}\end{array}$ & $\begin{array}{c}\text { total } \\
\text { energy } \\
\mathrm{kWh}\end{array}$ & $\begin{array}{c}\text { est. } \\
\text { range } \\
\mathrm{km}\end{array}$ & $\begin{array}{c}\text { relative } \\
\text { impact } \\
\%\end{array}$ \\
\hline EURO & 0.134 & 0.334 & 53 & $-40 \%$ \\
\hline Helsinki City & 0.236 & 0.402 & 44 & $-59 \%$ \\
\hline Artemis Urban & 0.256 & 0.494 & 36 & $-52 \%$ \\
\hline Road, FIN & 0.055 & 0.307 & 57 & $-18 \%$ \\
\hline Artemis Road, $\mathrm{EV}^{*}$ & 0.075 & 0.270 & 65 & $-28 \%$ \\
\hline Artemis Motorway, $\mathrm{EV}^{*}$ & 0.043 & 0.371 & 47 & $-11 \%$ \\
\hline
\end{tabular}

The eventual impact on the range is of course also marked, and employing the heater can further cut down the range by more than $50 \%$ in urban driving and by some $20 \%$ on $\mathrm{road} /$ motorway type of driving. At worst case the range can drop down to only $36 \mathrm{~km}$ (Artemis.Urban) with the heater full on.

\section{Acknowledgments}

The author acknowledges the invaluable help and expertise of Mr. Mikko Kallio and Mr. Ari-Pekka Pellikka for their expert efforts, ingenuity and time put into the instrumentation for these measurements. Furthermore, we owe our gratitude to Mr. Jukka Nuottimäki for orchestrating the tests, and last but not least to Mr Tommi Hangasmaa and Mr. Reijo Mikkola for the execution of tests at sometimes freezing conditions.

\section{References}

[1] http://www.teslamotors.com/roadster/specs, accessed on 28.2.2012.

[2] http://www.extremetech.com/extreme/ 118751-tesla-X-electric-motors, accessed on 28.2.2012.

[3] http://www.peugeot.co.uk/Resources/ Content/brochures/technical/peugeot-ion-pricesand-specifications.pdf, accessed on 28.02 . 2012

[4] http://en.wikipedia.org/wiki/Mitsubishi_iMiEV, accessed on 28.02.2012.

[5] http://green.autoblog.com/2010/06/14/nissanpegs-leaf-range-between-47-and-138-milesindividual-resu/, accessed on 28.02.2012.

\section{Authors}

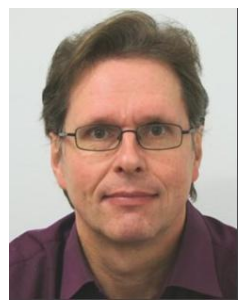

Dr. Juhani. Laurikko is a Principal Scientist at VTT. He received his M.Sc. (MechEng) in 1981, and Doctor of Technology (DTech) degree in 1998 from the Helsinki University of Technology. He joined VTT in 1985, and currently his principal areas of expertise are new propulsion technologies, alternative fuels and energy use in transportation.

BSc Arto Haakana is development manager at Green Net Finland. He began working with EV's in 1988 at Elcat Electric Vehicles. He has been expert in developing prototype EV's for Nordic conditions at European Batteries Ldt. 2008-2010, and at present he is coordinator of RekkEVidde project. 